\title{
980 - Phase State and Water Uptake Study of Individual Sea Spray Aerosol Particles Using Atomic Force Microscopy
}

\author{
Chathuri Kaluarachchi, Hansol Lee and Alexei Tivanski \\ University of Iowa, Iowa City, Iowa, United States
}

Sea spray aerosols (SSA) are produced via bubble bursting during wave breaking on the ocean surface, and have a wide range of size distribution from sub-micron to super-micron. ${ }^{1,2}$ SSA not only scatter and reflect solar radiation, but also can act as cloud condensation nuclei to facilitate formation of clouds. ${ }^{3}$ Since sub-micron SSAs have a longer life time in the atmosphere, they can show a considerable aerosol effects for a longer time compared to the super-micron SSAs. ${ }^{4}{ }^{5}$ During bubble bursting, organic, inorganic, and biological materials dissolved in bulk sea water can be transferred into SSA. ${ }^{2,6}$ Film and jet drops formation can control the size selective enrichment of surface active organic compounds in SSAs. As a result, SSA display significant particle-to-particle variability in the chemical composition and mixing states. These factors determine the water up-taking properties and phase states of SSA in a particular relative humidity $(\mathrm{RH}){ }^{6}$ Since, efficient water uptake can induce the growth of SSAs and formation of clouds, it is important to have single particle level techniques to assess particle-to-particle variability of these properties. Atomic force microscopy (AFM) will be an ideal tool to study single particle phase states and water uptake properties, because AFM has imaging capabilities up to $1 \mathrm{~nm}$ spatial resolution with 1 $\mathrm{pN}$ of force resolution on substrate-deposited particles. ${ }^{7}$ Moreover, AFM measurements can be performed under ambient temperature and pressure, as well as in controlled relative humidity (RH) conditions. Highresolution 3D height images, which will be produced during imaging in different $\mathrm{RH}$ conditions can be used to quantify the water uptake of individual particles. ${ }^{7-9}$ Moreover, force plots collected during each RH values can be used to quantify the phase states of the particles. Atomic force microscopy (AFM) is employed here to directly access the phase states and water up take ability of SSA particles as a function of RH on a single particle basis. In this study SSA were produced over the course of phytoplankton blooms in an isolated ocean-atmosphere facility containing 19,000 L of natural sea water with wave braking ability. Once produced, SSA were size selected and substrate deposited using micro orifice uniform deposition impactor (MOUDI) prior to the AFM studies. Here we show how phase states and water uptake vary as a function of particle size and evolve during the biological activity in sea water. 

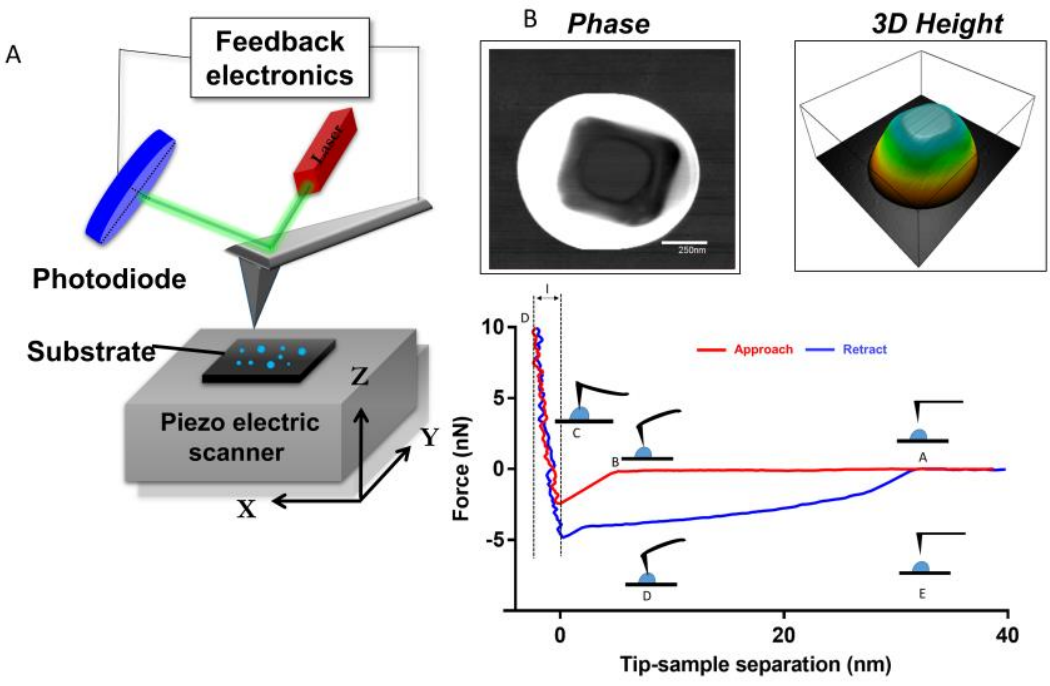

Figure 1. Figure 01 represents the Schematic diagrams of Atomic force microscopy (AFM) (A), Phase and 3D height image of a model $\mathrm{NaCl}$ : Glucose core-shell separated particle (B). Here dark color cube represents the salt, while white color outer shell represent the organic shell. Representative force plot obtained from the AFM on a model particle (C)

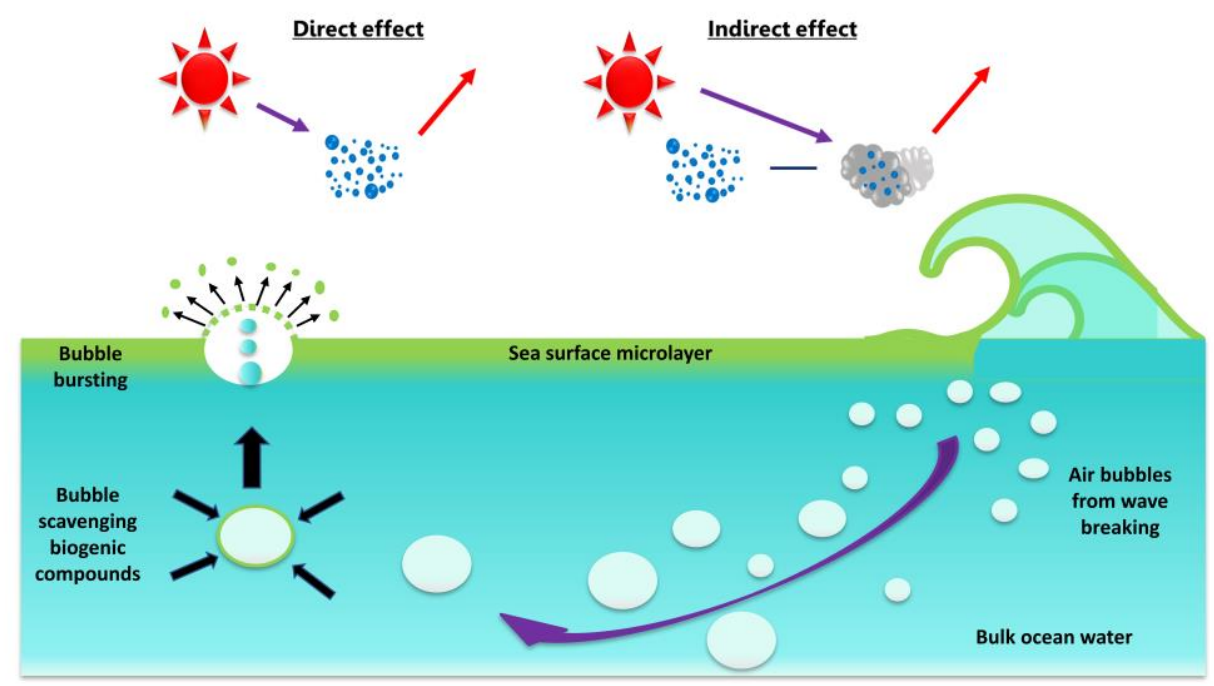

Figure 2. Figure 02. Shows the schematic diagram of ocean surface with sea surface micro layer and bulk water. This figure mainly focused on describing the bubble bursting at the water interface to form the sea spray aerosols and influence of those sea spray aerosols towards to the climatic changes.

\section{References}

Prather, K. A.; Bertram, T. H.; Grassian, V. H.; Deane, G. B.; Stokes, M. D.; DeMott, P. J.; Aluwihare, L. I.; Palenik, B. P.; Azam, F.; Seinfeld, J. H.; Moffet, R. C.; Molina, M. J.; Cappa, C. D.; Geiger, F. 
M.; Roberts, G. C.; Russell, L. M.; Ault, A. P.; Baltrusaitis, J.; Collins, D. B.; Corrigan, C. E.; CuadraRodriguez, L. A.; Ebben, C. J.; Forestieri, S. D.; Guasco, T. L.; Hersey, S. P.; Kim, M. J.; Lambert, W. F.; Modini, R. L.; Mui, W.; Pedler, B. E.; Ruppel, M. J.; Ryder, O. S.; Schoepp, N. G.; Sullivan, R. C.; Zhao, D., Bringing the ocean into the laboratory to probe the chemical complexity of sea spray aerosol. Proceedings of the National Academy of Sciences 2013, 110 (19), 7550.

2. Wang, X.; Deane, G. B.; Moore, K. A.; Ryder, O. S.; Stokes, M. D.; Beall, C. M.; Collins, D. B.; Santander, M. V.; Burrows, S. M.; Sultana, C. M.; Prather, K. A., The role of jet and film drops in controlling the mixing state of submicron sea spray aerosol particles. Proceedings of the National Academy of Sciences of the United States of America 2017, 114 (27), 6978-6983.

3. D., C. A.; R., O. S.; Jingchuan, Z., An ultrafine sea-salt flux from breaking waves: Implications for cloud condensation nuclei in the remote marine atmosphere. Journal of Geophysical Research: Atmospheres 2006, 111 (D6).

4. Vignati, E.; Facchini, M. C.; Rinaldi, M.; Scannell, C.; Ceburnis, D.; Sciare, J.; Kanakidou, M.; Myriokefalitakis, S.; Dentener, F.; O'Dowd, C. D., Global scale emission and distribution of seaspray aerosol: Sea-salt and organic enrichment. Atmospheric Environment 2010, 44 (5), 670-677 